\title{
Inadequate control of diabetes and metabolic indices among diabetic patients: A population based study from the Kerman Coronary Artery Disease Risk Study (KERCADRS)
}

\author{
Gholamreza Yousefzadeh $^{1}$, Mostafa Shokoohi ${ }^{2 *}$, Hamid Najafipour ${ }^{1}$
}

\begin{abstract}
Background: The goal of diabetes control should be feasible in order to minimize the risk of its adverse events and to reduce its burden and cost on patients. The current study aimed to assess the status of glycemic control in male and female patients with Type 2 Diabetes Mellitus (T2DM) in Kerman, Iran.

Methods: In the present study, 500 T2DM (300 women and 200 men) from the Kerman Coronary Artery Disease Risk Study (KERCADRS), a population-based study from 2009 to 2011, were selected. Patients were $>18$ years old, had Fasting Blood Sugar (FBS) higher than $126 \mathrm{mg} / \mathrm{dl}$, and had been through treatment for their diagnosed disease. All participants underwent Glycosylated Hemoglobin (HbAlc) analysis. HbAlc less than 7\% was considered as good glucose control. Other metabolic indices based on American Diabetes Association (ADA) target recommendations were considered.

Results: The mean level of HbAlc in total subjects was $8.56 \pm 4.72 \%$ that only $31.66 \%$ of men and $26.00 \%$ of women had controlled level of HbAlc. Total cholesterol less than $200 \mathrm{mg} / \mathrm{dl}$ was reported in $64.50 \%$ of men and $44.00 \%$ of women, High Density Lipoprotein (HDL) more than $40 \mathrm{mg} / \mathrm{dl}$ was revealed in $20.50 \%$ of men and $34.67 \%$ of women, and Low Density Lipoprotein (LDL) less than $100 \mathrm{mg} / \mathrm{dl}$ was reported in $41.50 \%$ of men and $25.33 \%$ of women. In multivariate logistic regression model, longer duration of disease and higher Waist Circumference (WC) were positively associated with uncontrolled diabetes status.

Conclusion: The findings of the present study revealed that diabetes control in T2DM was inadequate. Changing the policy of treatment in individual patient and establishing better diabetes clinic to decrease the frequency of uncontrolled T2DM are crucial. Paying attention to other affecting metabolic components such as WC in the process of T2DM management is important.

Keywords: Type 2 Diabetes Mellitus (T2DM), Diabetes Control, Glycosylated Hemoglobin (HbA1c), Diabetes Care, Central Obesity

Copyright: (C) 2015 by Kerman University of Medical Sciences

Citation: Yousefzadeh G, Shokoohi M, Najafipour H. Inadequate control of diabetes and metabolic indices among diabetic patients: A population based study from the Kerman Coronary Artery Disease Risk Study (KERCADRS). Int $J$ Health Policy Manag 2015; 4: 271-277. doi: 10.15171/ijhpm.2015.06
\end{abstract}

\section{Article History:}

Received: 7 September 2014

Accepted: 20 December 2014 ePublished: 23 December 2014

\section{*Correspondence to:}

Mostafa Shokoohi

Email: shokouhi.mostafa@gmail.com

\section{Key Messages}

Implications for policy makers

- Given the role of diabetes as an important health related problem in the community, appropriate policies and implementing up-to-date guidelines to better control this disease are unavoidable.

- Diabetes Mellitus (DM) is a complex disease which is correlated with other components of cardiovascular risk factors. So, the assessment of other risk factors like dietary pattern, and metabolic risk factors as well as two factors of Waist Circumference (WC) and the duration of the disease (which revealed the most important factors of inadequate control of Type 2 Diabetes Mellitus (T2DM) in the present study) should be considered in the process of the follow-ups of the patients to reach and achieve the treatment goals of $\mathrm{HbAlc}<7 \%$. Therefore, more effective management of the disease might be required.

Implications for public

In the present study, we found that the diabetes control was not adequate. However, the patients should realize that in most cases the inadequate diabetes control can have several causes such as: irregular use of medication, disregarding physician's recommendations to modify or change the trend of treatment in the course of disease, not paying enough attention to the role of nutrition, exercise/physical activity and weight loss in treatment program. Through making changes in the lifestyle of the public, the chance of controlling Type 2 Diabetes Mellitus (T2DM) can be considerably increased; consequently the probability of occurrence of other related diseases can be decreased. These simple (in theory) but difficult (in practice) tasks can be effective in preventing or delaying the onset of type 2 diabetes.

\section{Background}

Type 2 Diabetes Mellitus (T2DM) is a leading cause of morbidity worldwide, especially with increasing in its prevalence occurring in developing countries (1). The increasing trend of diabetes is not only dependent to the quality of medical care, follow-up of appropriate preventive and curative medication regimens as well as good dietary habits, but also can be influenced by aging, urbanization, and increasing prevalence of obesity and physical inactivity (2). According to the report of the World Health Organization 
(WHO) in 2000, about 170 million people suffered from diabetes worldwide and the number will be doubled by 2030 (3). Because of diabetes-related macrovascular, microvascular and neuropathic complications, a tight and consistent glycemic control can result lower complications and preventing its life-threatening events $(4,5)$. The goal for glycemic control should be feasible to minimize risk for adverse events and reduce load of complications and cost on patients $(6,7)$. Glycosylated Hemoglobin (HbA1c) index has become the gold standard for long-term monitoring glycemic control and is a validated measurement tool for assessing diabetes status. A HbA1c level $6.5 \%$ or less has been suggested as controlled Diabetes Mellitus (DM) (8-10). The HbA1c goal for diabetic patients has been generally considered less than $7 \%$, however recent guidelines have emphasized on more stringent goals, such as a normal HbAlc value of less than $6 \%$ especially in individual patients if they are achievable without significant hypoglycemia (11). It has been suggested that each percentage point increase in $\mathrm{HbA1c}$ results in a $10 \%$ increase in mortality from all forms of coronary heart disease and brain stroke (12). Diabetes is a common non-communicable disease among Iranian population with a prevalence of $7.7 \%$ in the middleage group and with poor quality of care expected for eye examination $(13,14)$. In 2002, more than 100,000 deaths were recorded as a consequence of diabetes in our country (15). Even, it is now more likely to be expanded earlier among children and teenagers so that a fasting blood glucose of more than $100 \mathrm{mg} / \mathrm{dl}$ has been detected in $4.1 \%$ of Iranian schoolage children and adolescents with the maximum prevalence between ages 10 and 14 (16). While, the prevalence of diabetes in 25 to 64 years old Iranian adults has been estimated to be $7.7 \%$, corresponding to about two million adults that only half of them are diagnosed $(17,18)$. In addition, the status of diabetes control in different urban and rural areas in our country has been already unknown and a few epidemiologicalbased studies have been conducted to identify trend of the diabetic control in our clinical settings. The present study was undertaken to assess the status of glycemic control and compare this index between male and female patients with T2DM by measurement of HbA1c in Kerman, the largest province in Iran, through a population-based study.

\section{Methods}

Participants

The Kerman Coronary Artery Disease Risk Study (KERCADRS) is a population-based, epidemiological research among a cohort of 5,900 individuals (3,238 women) aged between 15 to 75 years (from 2009 to 2011) and residence in Kerman city addressing the information of the risk profile of coronary artery disease including serum lipids, physical activity, alcohol and drugs addiction, mental disorders like stress and depression, hypertension as well as dietary regimens. The participants had been recruited through a household survey by non-proportional to the size one-stage cluster sampling. Non-communicable risk factors were collected by both a structured questionnaire (such as cigarette and opium smoking, obesity, hypertension, and so on) and laboratory measurements (such as HbA1C, Fasting Blood Sugar (FBS) and lipid profiles). Interviews were done by trained internal specialist, general practitioners, nurses and trained interviewers. [The methodology of this research has been published elsewhere] (19).

The participants of the current study were those diabetic patients with inclusion criteria of being older than 18 years, had FBS higher than $126 \mathrm{mg} / \mathrm{dl}$, and under treatment for their diagnosed disease. Additional information in regard to the epidemiology of diabetes, pre-diabetes, diagnosed and undiagnosed diabetes for the KERCADR study has been already published (20). All subjects were identified as having diabetes and/or using any hypoglycemic medication at the time of their recruitment into the study. Those with malignant disease, severe renal insufficiency, cirrhosis, active liver disease attributable to viral infection and/or other acute infectious or inflammatory disorders were all excluded.

\section{Clinical and biochemical examinations}

Participants underwent a biochemical examination that included measurement of $\mathrm{HbAlc}$, fasting glucose, systolic and diastolic blood pressure, serum triglyceride, and total, Low Density Lipoprotein (LDL), and High Density Lipoprotein (HDL) cholesterol. We examined weight and standing height expressed as Body Mass Index (BMI) (weight in kilograms divided by height in meters squared). The Waist Circumference (WC) was measured in a horizontal plane, midway between the inferior margin of the ribs and the superior border of the iliac crest. Blood pressure was recorded using an automatic oscillometric blood pressure recorder after at least 5 min of rest in a chair and arm supported at heart level. For biochemical analysis, blood samples of $5 \mathrm{ml}$ were drawn after $12 \mathrm{~h}$ overnight fasting for measuring lipid profile, FBS, and HbA1c. Plasma glucose was measured using the glucose oxidase peroxidase method. The level of serum lipid profile was also determined by standard enzymatic procedures. The primary indicator of glycemic control was level of HbAlc based on Biorad Variant High Performance Liquid Chromatography [HPLC] assay. This measure integrates control over the prior 12 weeks. In clinical practice, the goal for good control is $\mathrm{HbAlc}<7 \%$, although it may be as low as $6.5 \%$ in the absence of hypoglycemia or risk factors for hypoglycemia, as mentioned already (7). In the present study, controlled T2DM was considered as HbA1c $<7 \%$.

\section{Statistical analysis}

Results were presented as Mean \pm Standard Deviation (SD) for quantitative variables and were summarized by absolute frequencies and percentages for categorical variables. Categorical variables were compared using Chi-Square test or Fisher's exact test when more than $20 \%$ of cells with expected count of less than 5 were observed. Quantitative variables were also compared using T-Test or One-way analysis of variance (ANOVA) test. Multivariate logistic regression analysis was used to determine indicators of uncontrolled diabetes status adjusted for age, gender and diagnostic criteria. Statistical significance was determined as a $P<0.05$. All statistical analysis was performed using SPSS 20.0 (SPSS Inc., Chicago, Illinois).

\section{Results}

Table 1 shows the baseline men and women characteristics. There were more females $(60.00 \%)$ than males $(40.00 \%)$. 
Table 1. Baseline characteristics of study population with DM $(n=500)$

\begin{tabular}{|c|c|c|c|}
\hline Characteristics & Men $(n=200)$ & Women $(n=300)$ & $P$-value \\
\hline Age (year) & $60.43 \pm 10.87$ & $58.58 \pm 9.83$ & 0.055 \\
\hline Weight (kg) & $76.32 \pm 13.18$ & $70.70 \pm 13.35$ & $<0.001$ \\
\hline Height $(\mathrm{cm})$ & $169.95 \pm 7.96$ & $157.09 \pm 5.88$ & $<0.001$ \\
\hline BMI $\left(\mathrm{kg} / \mathrm{m}^{2}\right)$ & $26.47 \pm 4.68$ & $28.60 \pm 4.91$ & $<0.001$ \\
\hline WC $(\mathrm{cm})$ & $90.82 \pm 11.77$ & $94.28 \pm 10.64$ & 0.001 \\
\hline Systolic blood pressure (mmHg) & $131.11 \pm 20.50$ & $131.92 \pm 21.72$ & 0.673 \\
\hline Diastolic blood pressure (mmHg) & $81.52 \pm 10.05$ & $81.49 \pm 10.51$ & 0.980 \\
\hline $\mathrm{FBS}(\mathrm{g} / \mathrm{dl})$ & $163.04 \pm 62.72$ & $171.05 \pm 70.60$ & 0.203 \\
\hline Triglyceride (mg/dl) & $185.14 \pm 138.13$ & $198.74 \pm 162.32$ & 0.323 \\
\hline $\mathrm{HDL}$ (mg/dl) & $34.26 \pm 8.59$ & $38.54 \pm 9.52$ & $<0.001$ \\
\hline $\mathrm{LDL}(\mathrm{mg} / \mathrm{dl})$ & $115.22 \pm 38.68$ & $136.59 \pm 44.06$ & $<0.001$ \\
\hline HbA1c (\%) & $8.66 \pm 5.98$ & $8.50 \pm 3.71$ & 0.738 \\
\hline
\end{tabular}

$\mathrm{DM}=$ Diabetes Mellitus; BMI= Body Mass Index; WC= Waist Circumference; FBS= Fasting blood sugar; HDL= High Density Lipoprotein; LDL= Low Density Lipoprotein; HbA1c= Glycosylated Hemoglobin.

The overall mean age was $59.32 \pm 10.29$ years (median 59 years, ranged 23 to 86 years) that men were slightly elder than women ( 60.43 years versus 58.58 years, $P=0.055$ ). The mean duration of diabetes was 68.84 months in men and 65.03 months in women $(P=0.540)$. Insulin users comprised $11.81 \%$ of the study population (men $13.42 \%$, women $10.21 \%$ ), while multiple oral medication users were $84.90 \%$ (men $83.80 \%$, women $86.00 \%$ ) and others followed both controlling approaches (men $2.82 \%$, women $3.71 \%$ ). Mean BMI and WC were significantly more prevalent in women than men $(P<0.001)$.

Mean systolic and diastolic blood pressures were totally 130.65 $\pm 21.13 \mathrm{mmHg}$ and $81.02 \pm 10.26 \mathrm{mmHg}$, respectively that were statistically similar in both genders. Among lipid profile, the mean levels of total cholesterol and LDL were higher in women than men, whereas no differences were observed across them in terms of serum levels of triglyceride and FBS. The current status of $\mathrm{HbAlc}$ in both genders is presented in Table 2. The mean level of HbA1c in total subjects was 8.56 $\pm 4.72 \%$ (mean $7.80 \%$ ) that only $31.66 \%$ of men and $26 \%$ of women had controlled level of HbAlc $(<7 \%)$.

With respect to the status of controlling blood sugar and lipid profile in men and women (Table 3 ) and based on American Diabetes Association (ADA) target recommendations, $34.50 \%$ of men and $35.67 \%$ of women achieved FBS $<130 \mathrm{mg} /$ $\mathrm{dl}$ and thus meeting the goal. Also, regarding control of lipid

Table 2. HbA1c status in men and women with DM

\begin{tabular}{lcc}
\hline HbA1c & Men $(\mathbf{n}=\mathbf{2 0 0})$ & Women $(\mathbf{n}=\mathbf{3 0 0})$ \\
\hline$<7.0 \%$ & $63(31.66)$ & $78(26.00)$ \\
$7.0-7.9 \%$ & $49(24.62)$ & $80(26.67)$ \\
$8.0-8.9 \%$ & $37(18.59)$ & $47(15.67)$ \\
$9.0-9.9 \%$ & $20(10.05)$ & $36(12.00)$ \\
$10.0-10.9 \%$ & $12(6.03)$ & $31(10.33)$ \\
$11.0-11.9 \%$ & $10(5.03)$ & $17(5.67)$ \\
$\geq 12.0 \%$ & $8(4.02)$ & $11(3.67)$ \\
\hline
\end{tabular}

$\mathrm{HbA} 1 \mathrm{c}=$ Glycosylated Hemoglobin; DM= Diabetes Mellitus. $P=0.510$. profile, total cholesterol less than $200 \mathrm{mg} / \mathrm{dl}$ was reported in $64.50 \%$ of men and $44.00 \%$ of women, HDL more than 40 $\mathrm{mg} / \mathrm{dl}$ was revealed in $20.50 \%$ of men and $34.67 \%$ of women, and LDL less than $100 \mathrm{mg} / \mathrm{dl}$ was reported in $41.50 \%$ of men

Table 3. Status of blood sugar and lipid profile in men and women with DM

\begin{tabular}{|c|c|c|}
\hline Item & Men $(n=200)$ & Women $(n=300)$ \\
\hline \multicolumn{3}{|l|}{ FBS } \\
\hline$<130 \mathrm{~g} / \mathrm{dl}$ & $69(34.50)^{*}$ & 107 (35.67) \\
\hline$\geq 130 \mathrm{~g} / \mathrm{dl}$ & $131(65.50)$ & $193(64.33)$ \\
\hline \multicolumn{3}{|l|}{ Total cholesterol } \\
\hline$<200 \mathrm{mg} / \mathrm{dl}$ & $129(64.50)$ & $132(44.00)$ \\
\hline$\geq 200 \mathrm{mg} / \mathrm{dl}$ & $71(35.50)$ & $168(56.00)$ \\
\hline \multicolumn{3}{|l|}{$\mathrm{HDL}$} \\
\hline$>40 \mathrm{mg} / \mathrm{dl}$ & $41(20.50)$ & $104(34.67)$ \\
\hline$\leq 40 \mathrm{mg} / \mathrm{dl}$ & $159(79.50)$ & $196(65.33)$ \\
\hline \multicolumn{3}{|l|}{ LDL } \\
\hline$<100 \mathrm{mg} / \mathrm{dl}$ & $83(41.50)$ & $76(25.33)$ \\
\hline$\geq 100 \mathrm{mg} / \mathrm{dl}$ & $117(58.50)$ & $224(74.67)$ \\
\hline \multicolumn{3}{|l|}{ Triglyceride } \\
\hline$<150 \mathrm{mg} / \mathrm{dl}$ & $107(53.50)$ & $111(37.00)$ \\
\hline$\geq 150 \mathrm{mg} / \mathrm{dl}$ & $93(46.50)$ & $189(63.00)$ \\
\hline \multicolumn{3}{|l|}{$\mathrm{BMI}$} \\
\hline$<30 \mathrm{~kg} / \mathrm{m}^{2}$ & $165(82.50)$ & $203(67.67)$ \\
\hline$\geq 30 \mathrm{~kg} / \mathrm{m}^{2}$ & $35(17.50)$ & $97(32.33)$ \\
\hline \multicolumn{3}{|c|}{ Systolic blood pressure } \\
\hline$<130 \mathrm{mmHg}$ & $81(40.50)$ & $136(45.33)$ \\
\hline$\geq 130 \mathrm{mmHg}$ & $119(59.50)$ & $164(54.67)$ \\
\hline \multicolumn{3}{|c|}{ Diastolic blood pressure } \\
\hline$<90 \mathrm{mmHg}$ & $54(27.00)$ & $84(28.00)$ \\
\hline$\geq 90 \mathrm{mmHg}$ & $146(73.00)$ & $216(72.00)$ \\
\hline
\end{tabular}

FBS= Fasting blood sugar; $\mathrm{DM}=$ Diabetes Mellitus; $\mathrm{HDL}=$ High Density Lipoprotein; LDL= Low Density Lipoprotein; BMI= Body Mass Index. ${ }^{*} \mathrm{n}(\%)$. 
and $25.33 \%$ of women.

Univariate associations of baseline factors with glycemic control are shown in Table 4. Those with lower total triglyceride level (less than $150 \mathrm{mg} / \mathrm{dl}$ ) had lower mean HbAlc value (7.94\%) than those with higher total triglyceride levels (9.02\%). Also, mean HbA1c level was lower in patients with LDL level lower than $100 \mathrm{mg} / \mathrm{dl}$ (8.08\%) compared to those with higher LDL level $(8.77 \%)$. On the other hand, the main indicators of uncontrolled diabetes according to $\mathrm{HbAlc}$ values were high triglyceride and LDL levels. In multivariate logistic regression model adjusted for background parameters (Table 5), higher duration of disease and higher WC were positively associated with uncontrolled diabetes status. However, higher lipid profile levels or medications

Table 4. Mean level of hemoglobin A1c in different risk profile

\begin{tabular}{|c|c|c|}
\hline Item & Mean A1c & P-value \\
\hline \multicolumn{3}{|l|}{ Gender } \\
\hline Men & $8.66 \pm 5.98^{*}$ & 0.738 \\
\hline Women & $8.50 \pm 3.71$ & \\
\hline \multicolumn{3}{|l|}{ Age } \\
\hline$<50$ years & $8.22 \pm 2.02$ & \\
\hline 50-65 years & $8.43 \pm 3.65$ & 0.386 \\
\hline$>65$ years & $9.05 \pm 7.30$ & \\
\hline \multicolumn{3}{|l|}{ Disease duration } \\
\hline$<1$ years & $8.22 \pm 5.83$ & \\
\hline $1-5$ years & $9.04 \pm 6.43$ & 0.596 \\
\hline $6-10$ years & $8.50 \pm 1.86$ & \\
\hline$>10$ years & $8.76 \pm 1.67$ & \\
\hline \multicolumn{3}{|c|}{ Diabetes control method } \\
\hline Insulin & $8.36 \pm 1.43$ & \\
\hline Oral medication & $8.76 \pm 4.88$ & 0.811 \\
\hline Both & $9.26 \pm 2.08$ & \\
\hline \multicolumn{3}{|l|}{ Total cholesterol } \\
\hline$<200 \mathrm{mg} / \mathrm{dl}$ & $8.44 \pm 5.30$ & 0.547 \\
\hline$\geq 200 \mathrm{mg} / \mathrm{dl}$ & $8.69 \pm 4.03$ & \\
\hline \multicolumn{3}{|l|}{ HDL } \\
\hline$>40 \mathrm{mg} / \mathrm{dl}$ & $8.33 \pm 1.82$ & 0.328 \\
\hline$\leq 40 \mathrm{mg} / \mathrm{dl}$ & $8.66 \pm 5.50$ & \\
\hline \multicolumn{3}{|l|}{ LDL } \\
\hline$<100 \mathrm{mg} / \mathrm{dl}$ & $8.08 \pm 1.65$ & 0.034 \\
\hline$\geq 100 \mathrm{mg} / \mathrm{dl}$ & $8.77 \pm 5.53$ & \\
\hline \multicolumn{3}{|l|}{ Triglyceride } \\
\hline$<150 \mathrm{mg} / \mathrm{dl}$ & $7.94 \pm 1.75$ & 0.005 \\
\hline$\geq 150 \mathrm{mg} / \mathrm{dl}$ & $9.02 \pm 5.99$ & \\
\hline \multicolumn{3}{|l|}{ BMI } \\
\hline$<30 \mathrm{~kg} / \mathrm{m}^{2}$ & $8.55 \pm 4.51$ & 0.920 \\
\hline$\geq 30 \mathrm{~kg} / \mathrm{m}^{2}$ & $8.60 \pm 5.27$ & \\
\hline \multicolumn{3}{|c|}{ Systolic blood pressure } \\
\hline$<130 \mathrm{mmHg}$ & $8.79 \pm 5.69$ & 0.375 \\
\hline$\geq 130 \mathrm{mmHg}$ & $8.39 \pm 3.81$ & \\
\hline \multicolumn{3}{|c|}{ Diastolic blood pressure } \\
\hline$<90 \mathrm{mmHg}$ & $8.74 \pm 5.09$ & 0.625 \\
\hline$\geq 90 \mathrm{mmHg}$ & $8.49 \pm 4.58$ & \\
\hline
\end{tabular}

$\overline{\mathrm{HDL}}=$ High Density Lipoprotein; LDL= Low Density Lipoprotein; BMI= Body Mass Index.

${ }^{*}$ Mean \pm standard deviation.
Table 5. Multiple model for determining indicators of uncontrolled DM

\begin{tabular}{lccc}
\hline Characteristics & Odds Ratio & $95 \% \mathrm{Cl}$ & $P$-value \\
\hline Male gender & 0.80 & $0.32-2.00$ & 0.637 \\
Age & 0.99 & $0.95-1.03$ & 0.799 \\
BMI & 0.94 & $0.85-1.05$ & 0.264 \\
WC & 1.06 & $1.00-1.11$ & 0.038 \\
Disease duration & 1.01 & $1.00-1.02$ & 0.016 \\
Diabetes control regimen & 0.62 & $0.14-2.06$ & 0.514 \\
Systolic blood pressure & 0.99 & $0.96-1.01$ & 0.356 \\
Diastolic blood pressure & 1.02 & $0.96-1.08$ & 0.482 \\
LDL & 0.99 & $0.99-1.01$ & 0.868 \\
Total triglyceride & 1.00 & $0.99-1.01$ & 0.910 \\
\hline
\end{tabular}

$\mathrm{DM}=$ Diabetes Mellitus; $\mathrm{BMI}=$ Body Mass Index; $\mathrm{WC}=$ Waist Circumference; HDL= High Density Lipoprotein; LDL= Low Density Lipoprotein; HbA1c= Glycosylated Hemoglobin.

for controlling diabetes could not predict uncontrolled diabetes status.

\section{Discussion}

The findings of our study show that of the total study diabetes patients, only $31.6 \%$ of men and $26 \%$ of women have acceptable HbA1c values of $<7 \%$. The remaining ones have values above the recommended cut-off and hence an undesirable diabetic control status. This result demonstrated a notable high prevalence rate of uncontrolled diabetes when compared with other similar reports, but is in agreement with other reports from different regions of our country. In a similar study originated from Iran's national noncommunicable diseases risk factor surveillance survey, about 97.4\% of the patients had poor control according to their most recent HbA1c levels. In this regard, about 25\% needed an improvement in diabetes control according to their blood levels of LDLs, and 45\% of them were hypertensive (21). But, better diabetes control has been reported from south Asian, European and Western countries. Chuang et al. showed that $55 \%$ of the patients from South Asian countries had HbA1c values exceeding $8 \%(22)$. A retrospective analysis of data from 1998-2002 in UK found that $>60 \%$ of the patients had poorly controlled disease regardless of the cut-off used to determine good control (23), while a Canadian study demonstrated $\mathrm{HbA1c}$ of $7.7 \%$ for $78 \%$ of the patients tested (24). The average $\mathrm{HbA} 1 \mathrm{c}$ for patients in Australian population was $7.3 \pm 1.23(25)$. The results of a European cohort study (RECAP-DM) in 2008 showed that the overall frequency of adequate glycemic control among 2,023 T2DM patients was one quarter (25.5\%) (26). In another international longitudinal study (IDMP study) among 11,799 diabetic patients, recruited from 17 developing countries in 2009, results illustrated that only $20-30 \%$ of patients achieved the goal of less than $7 \%$ for HbA1c (27). The findings of a recent multicenter, cross-sectional survey of outpatients carried out in 606 hospital in all provinces of China among more than 230 thousands T2DM demonstrated that less than one third of the patients achieved the goal of HbA1c less than 7\% (28). Regarding associated indicators of poor controlled diabetes, we evaluated some clinical criteria and found that only higher duration of disease and higher WSs were associated with this poor diabetes controlling. However, we did not 
consider socio-economic characteristics for this aim that might be powerful indicators. On the other hand, the most important factor associated with poor control diabetes status can be some clinical risk profiles including central obesity and disease duration, however potential effects of some other determinants such as inadequate knowledge of patients and even care providers should not be ignored. According to some surveys, lack of adequate knowledge about the disease is a principle affecting factor. In this regard, in a study among Pakistani diabetic population, 58\% of the patients lacked appropriate education for disease management that also had the highest levels of HbA1c of 9.98\% (29). Another main factors pointed in other studies was financial burden imposed on the patients accounts for the majority of the patients with suboptimum HbA1c levels. Inaccessibility to healthcare facilities, psychosocial influences, low level of self-care, and no adherence to treatment are other limiting factors for developing countries (30-33).

Regarding association between obesity (high WC) and poor diabetes control, it has been suggested that adults with insulin dependent diabetes are often obese, and this may adversely affect their diabetic control, resulting in complications (34). WC alone has been identified as a strong determinant for glucose exacerbation and glycemic relapse among people with T2DM and more predictive than other components of metabolic syndrome (35), although BMI was also another powerful predictor of insulin resistance (36) and poor control of diabetes. Blaha et al. (35) showed that WC had a positive significant correlation with increased risk of hyperglycemic recurrence in both simple analysis (hazard ratio: 3.4) and multivariate analysis (hazard ratio: 3.2 ). Such findings was recognized in a study by Janiszewski et al. (37), which in a cross-sectional study among around 6,000 individuals from the U.S. showed that WC was significantly considered as a major predictor of blood glucose levels. Obesity along with other risk factors such as physical inactivity and unsound diet regime have been known as significant determinants of insulin resistance and beta-cell failure (as physiologic factors), which can consequently lead to inadequate T2DM control (38).

We found a direct association between poor diabetes control and disease duration. Similarly, Otiniano et al. (39) found that subjects with poor control had longer disease duration, had lower education, used the glucometer more frequently, and had more diabetes-complications when compared to those in the good glycemic control group. In the multivariable analysis, longer disease duration besides low educational level, foreign-born, smoking, obesity, daily glucometer use, and having macro-complications were main determinants of poor diabetes control. Study by Longo-Mbenz et al. (40) duration diabetes $\geq 4$ years was significantly associated with the presence of diabetic complications and its inappropriate controlling. In a study in Jordan among patients with T2DM, it was shown two factors of longer duration of DM and poor adherence to behaviors related to self-care management were significantly (in the multivariate analysis) associated with inadequate control of DM, which around two third of the T2DM patients had $\mathrm{HbA1c} \geq 7 \%$ (41). Our results were consistent with the findings of these studies. It has been studied that advanced age and duration of diabetes have a significant association with increased likelihood of insulin resistance and levels of HbA1c (42). It is determined that aging and longer duration of diabetes are significant predictors of uncontrolled HbA1c which may lead to chronic hyperglycemic and insulin insensitivity (43). The main cause of this association might be related to more highlighted effect of longer diabetes duration and higher prevalence of other diabetes disease risk factors such as hyperlipidemia as well as complication of disease that can potentially result in more severe disease status and more severe disease control.

Although we did not obtain any relationship between poor glycemic control and type of treatment approach of diabetes, some authors showed that the subgroup of patients not treated with insulin presented relatively lower rates of poor glycemic control, while those with type 2 diabetes using insulin had a prevalence of inadequate glycemic control. One survey by Arai et al. (44) in Japan and another study by Yu et al. (45) in Taiwan also reported lower mean levels of HbA1c among patients not requiring insulin. These differences changed after stratifying the data by diabetes duration, but even among patients at earlier stage of diabetes ( $<5$ years duration) insulin treatment was associated with worse control when compared to diet alone or combined with oral treatment, possibly due to more severe and more difficult to control diabetes in the former patients.

We found no significant difference in glycemic control by gender. Several studies have failed to show significant gender differences related to self-care and control of diabetes (46-49). Contrarily, in a study in a Pakistani Muslim diabetic population in UK, women were worse than men in performing regular glucose measurements, in managing persistent hyperglycemia, and had also poorer glycemic control overall (HbA1c $8.8 \%$ vs. $8.1 \%, P<0.05$ ) (50). Results from a survey in Mexico have suggested that women have several social disadvantages, deterioration of healthy life, poor self-care and lack of solidarity that increases their vulnerability to reach glycemic control successfully (51).

\section{Strengths and limitations}

The distinctive strengths of this study are the large provincial sample, the data collection by trained and certified interviewers from general practitioners not part of the local center staff, and the measurement of HbAlc by a reliable method in a single central laboratory. Despite that, one limitation is that the study did not assess most of socioeconomic factors for determining indicators of poor diabetes control such as their education level, income, level of physical activity, and dietary habits.

\section{Conclusion}

Diabetes control in these Kermanian diabetic patients is not adequate as shown by very high rates of poor control of $\mathrm{HbAlc}$, because of poor diabetes care and management. Longer diabetes duration and obesity are significantly associated with poor control of diabetes.

\section{Acknowledgments}

This study was part of the KERCADRS study approved by the Physiology Research Center and research deputy of Kerman 
University of Medical Sciences (KMU). The authors would like to thank all subjects who participated in this study and all interviewers and colleagues who helped us to collect the data.

\section{Ethical issues}

The study was approved by the research ethics committees at Kerman University of Medical Sciences (KUMS) and informed consent was obtained from all participants.

\section{Competing interests}

The authors declare that they have no competing interests.

\section{Authors' contributions}

GY and MS were responsible for study concept and design. HN was responsible for data gathering and data management process. MS performed data analysis. GY, MS, and HN produced interpretations of findings. GY and MS drafted the manuscript and all authors provided important feedback and approved the final version.

\section{Authors' affiliations}

${ }^{1}$ Physiology Research Center, Institute of Neuropharmacology, Kerman University of Medical Sciences, Kerman, Iran. ${ }^{2}$ Research Center for Modeling in Health, Institute for Futures Studies in Health, Kerman University of Medical Sciences, Kerman, Iran.

\section{References}

1. Hossain P, Kawar B, El Nahas M. Obesity and diabetes in the developing world-A growing challenge. N Engl J Med 2007; 356: 213-5. doi: 10.1056/nejmp068177

2. UK Prospective Diabetes Study (UKPDS) Group. Intensive blood-glucose control with sulphonylureas or insulin compared with conventional treatment and risk of complications in patients with type 2 diabetes (UKPDS 33). Lancet 1998; 352: 837-53. doi: 10.1016/s0140-6736(98)07019-6

3. Wild S, Roglic G, Green A, Sicree R, King H. Global prevalence of diabetes: estimates for the year 2000 and projections for 2030. Diabetes Care 2004; 27: 1047-53. doi: 10.2337/ diacare.27.5.1047

4. The Diabetes Control and Complications Trial Research Group. The effect of intensive treatment of diabetes on the development and progression of long term complications in insulin-dependent diabetes mellitus. N Engl J Med 1993; 329: 977-86. doi: 10.1056/ NEJM199309303291401

5. Diabetes Control and Complications Trial/Epidemiology of Diabetes Interventions and Complications (DCCT/EDIC) Study Research Group. Intensive diabetes treatment and cardiovascular disease in patients with type 1 diabetes. N Engl J Med 2005; 353: 2643-53. doi: 10.1161/circulationaha.111.077487

6. Qaseem A, Vijan S, Snow V, Cross JT, Weiss KB, Owens $\mathrm{DK}$, et al. Glycemic control and type 2 diabetes mellitus: the optimal hemoglobin A1c targets. A guidance statement from the American College of Physicians. Ann Intern Med 2007; 147 : 417-22. doi: 10.7326/0003-4819-147-6-200709180-00012

7. American Diabetes Association. Standards of medical care in diabetes-2013. Diabetes Care 2013; 36: S11-66. doi: 10.2337/ dc13-s011

8. American Association of Clinical Endocrinologists. The American Association of Clinical Endocrinologists Medical Guidelines for the Management of Diabetes Mellitus: the AACE System of Intensive Diabetes Self-Management-2002 Update. Endocr Pract 2002; 8: 40-82. doi: 10.2337/dc13-s011

9. Stratton IM, Adler AI, Neil HA, Matthews DR, Manley SE, Cull $\mathrm{CA}$, et al. Association of glycemia with microvascular and macro vascular complications of type 2 diabetes mellitus (UKPDS 35): prospective observational study. BMJ 2000; 321: 405-12.
10. Klein R, Klein BE, Moss SE. Relation of glycemic control to diabetic microvascular complications in diabetes mellitus. Ann Intern Med 1996; 124: 90-6. doi: 10.7326/0003-4819-124-1_ part 2-199601011-00003

11. Gilmer TP, O'Connor PJ, Manning WG, Rush WA. The cost to health plans of poor glycemic control. Diabetes Care 1997; 20: 1847-53. doi: 10.2337/diacare.20.12.1847

12. Klein R. Hyperglycemia and microvascular and macrovascular disease in diabetes. Diabetes Care 1995; 18: 258-68. doi: 10.2337/diacare.18.2.258

13. Azizi F, Gouya MM, Vazirian P, Dolatshahi P, Habibian S. The diabetes prevention and control programme of the Islamic Republic of Iran. East Mediterr Health J 2003; 9: 1114-21.

14. Delavari A, Alikhani S, Nili S, Birjandi RH, Birjandi F. Quality of care of diabetes mellitus type II patients in Iran. Arch Iran Med 2009; 12: 492-5.

15. Delavari AR. [National Program for Control and Prevention of Diabetes]. Tehran: Center for Disease Control; 2004. [In Persian]

16. Agency for Healthcare Research and Quality (AHRQ). Quality Indicators - Guide to Patient Safety Indicators. No. 03-R203, Revision 2. Rockville, MD: Agency for Healthcare Research and Quality; 2004.

17. Kelishadi R, Ardalan G, Gheiratmand R, Adeli K, Delavari A, Majdzadeh R, The Caspian Study Group.Paediatric metabolic syndrome and associatedanthropometric indices: the CASPIAN Study. Acta Paediatr 2006; 95: 1625-34. doi: 10.1080/08035250600750072

18. Esteghamati A, Gouya MM, Abbasi M, Delavari A, Alikhani S, Alaedini F. Prevalence of diabetes and impaired fasting glucose in the adult population of Iran: National Survey of Risk Factors for Non-CommunicableDiseases of Iran. Diabetes Care 2008. 31: 96-8. doi: 10.2337/dc07-0959

19. Najafipour H, Mirzazadeh A, Haghdoost A, Shadkam M, Afshari M, Moazenzadeh M, et al. Coronary Artery Disease Risk Factors in an Urban and Peri-urban Setting, Kerman, Southeastern Iran (KERCADR Study): Methodology and Preliminary Report. Iranian J Public Health 2012; 41: 86-92

20. Najafipour $H$, Sanjari $M$, Shokoohi $M$, Haghdoost AA, Afshari $M$, Shadkam $M$, et al. Epidemiology of diabetes mellitus, pre-diabetes, undiagnosed and uncontrolled diabetes and its predictors in general population aged 15 to 75 years: A community-based study (KERCADRS) in southeastern Iran. J Diabetes 2014; 15. doi: 10.1111/1753-0407.12195

21. Delavari A, Alikhani S, Nili S, Birjandi RH, Birjandi F. Quality of care of diabetes mellitus type II patients in Iran. Arch Iranian Med 2009; 12: 492-5.

22. Chuang LM, Tsai ST, Huang BY, Tai TY. The status of diabetes control in Asia-a cross sectional survey of 24317 patients with diabetes mellitus in 1998. Diabetic Med 2002; 19: 978-85. doi: 10.1046/j.1464-5491.2002.00833.x

23. Fox KM, Gerber RA, Bolinder B, Chen J, Kumar S. Prevalence of inadequate Glycemic control among patients with diabetes in the United Kingdom general practice research data base: a series of retrospective analysis of data from 1998-2002. Clinl Ther 2006; 28: 388-95. doi: 10.1016/j.clinthera.2006.03.005

24. Harris SB, Worrall G, Macaulay A, Norton P, Webster-Bogaert S, Donner A, et al. Diabetes Management in Canada: Baseline Results of the Group Practice Diabetes Management Study. Can J Diabetes 2006; 30: 131-7. doi: 10.1016/s1499-2671(06)02005-3

25. Mark T, Andrew J, Merlin C. The management of diabetes in Indigenous Australians from primary care. BMC Public Health 2007; 7: 303. doi: 10.1016/s1499-2671(06)02005-3

26. Alvarez Guisasola F, Mavros P, Nocea G, Alemao E, Alexander $\mathrm{CM}$, Yin D. Glycaemic control among patients with type 2 diabetes mellitus in seven European countries: findings from the Real-Life Effectiveness and Care Patterns of Diabetes 
Management (RECAP-DM) study. Diabetes Obes Metab 2008; 10: 8-15. doi: 10.1111/j.1463-1326.2008.00881.x

27. Chan JC, Gagliardino JJ, Baik SH, Chantelot JM, Ferrera SR, Hancu N, et al. Multifaceted determinants for achieving glycemic control: The international diabetes management practice study (IDMPS). Diabetes Care 2009; 32: 227-33. doi: 10.2337/dc080435

28. Ji LN, Lu JM, Guo XH, Yang WY, Weng JP, Jia WP, et al. Glycemic control among patients in China with type 2 diabetes mellitus receiving oral drugs or injectables. BMC Public Health 2013; 13 : 602. doi: $10.2337 / \mathrm{dc} 08-0435$

29. Afridi MA, Khan MN. Role of health education in the management of diabetes mellitus. J Coll Physician Surg Pak 2003; 13: 558-61.

30. Sarkadi A, Rosenqvist U. Fiels test of a group education program for type 2 diabetes: measures and predictors of successon individual and group levels. Patient Educ Counseling 2001; 4: 129-39.

31. Gilden JL, Hendryx M, Casia C, Singh SP. The effectiveness of diabetes education programs for older patients and their spouses. J Am Geriatr Soc 1989; 37: 1023-30.

32. Gilden JL, Hendryx MS, Clar S, Casia C, Singh SP. Diabetes support groups improve health care of older diabetic patients. $J$ Am Geriatr Soc 1992; 40: 147-50.

33. Mazzuca SA, Moorman NH, Wheeler ML, Norton JA, Fineberg NS, Vinicor F, Cohen SJ, et al. The diabetes educationstudy: a controlled trial of the effectsof diabetes patient education. Diabetes Care 1986; 9: 1-10.

34. Hundley JM. Diabetes-overweight: US problems. J Am Diet Assoc 1956; 32: 417-22.

35. Blaha MJ, Gebretsadik T, Shintani A, Elasy TA. Waist circumference, not the metabolic syndrome, predicts glucose deterioration in type 2 diabetes. Obesity (Silver Spring) 2008; 16: 869-74. doi: 10.1038/oby.2008.12

36. Farin HM, Abbasi F, Reaven GM. Body mass index and waist circumference correlate to the same degree with insulinmediated glucose uptake. Metabolism 2005; 54: 1323-8. doi: 10.1016/j.metabol.2005.04.021

37. Janiszewski PM, Janssen I, Ross R. Does waist circumference predict diabetes and cardiovascular disease beyond commonly evaluated cardiometabolic risk factors? Diabetes Care 2007; 30: 3105-9. doi: $10.2337 / \mathrm{dc0}$-0945

38. Kyrou I, Kumar S. Weight management in overweight and obese patients with type 2 diabetes mellitus. Br J Diabet Vasc Dis 2010; 10: 274-83. doi: $10.1177 / 1474651410388976$

39. Otiniano ME, Al Snih S, Goodwin JS, Ray L, Alghatrif M, Markides KS. Factors associated with poor glycemic control in older Mexican American diabetics aged 75 years and older. J Diabetes Complications 2012; 26: 181-6. doi: 10.1016/j. jdiacomp.2012.03.010

40. Longo-Mbenz B, Muak MM, Mbenza G. Risk factors of poor control of HBA1c and diabetic retinopathy: Paradox with insulin therapy and high values of HDL in African diabetic patients. International Journal of Diabetes Metabolism 2008; 16: 69-78.

41. Khattab M, Khader YS, Al-Khawaldeh A, Ajlouni K. Factors associated with poor glycemic control among patients with type 2 diabetes. J Diabetes Complications 2010; 24: 84-9. doi: 10.1016/j.jdiacomp.2008.12.008

42. Verma M, Paneri S, Badi P, Raman PG. Effect of increasing duration of diabetes mellitus type 2 on glycated hemoglobin and insulin sensitivity. Indian J Clin Biochem 2006; 21: 142-6. doi: 10.1016/j.jdiacomp.2008.12.008

43. Kilpatrick ES, Dominiczak MH, Small M. The effects of ageing on glycation and the interpretation of glycaemic control in Type 2 diabetes. QJM 1996; 89: 307-12. doi: 10.1093/qjmed/89.4.307

44. Yu NC, Su HY, Tsai ST, Lin BJ, Shiu RS, Hsieh YC, et al. ABC control of diabetes: survey data from National Diabetes Health Promotion Centers in Taiwan. Diabetes Res Clin Pract 2009; 84: 194-200. doi: 10.1016/j.diabres.2009.02.020

45. Arai K, Hirao K, Matsuba I, Takai M, Matoba K, Takeda H, et al. The status of glycemic control by general practitioners and specialists for diabetes in Japan: a cross sectional survey of 15,652 patients with diabetes mellitus, Diabetes Res Clin Pract 2009; 83: 397-401. doi: 10.1016/j.diabres.2008.11.036

46. Fox KM, Gerber Pharmd RA, Bolinder B, Chen J, Kumar S. Prevalence of inadequate glycemic control among patients with type 2 diabetes in the United Kingdom general practice research database: a series of retrospective analyses of data from 1998 through 2002. Clin Ther 2006; 28: 388-95. doi: 10.1016/j. clinthera.2006.03.005

47. Goudswaard AN, Stolk RP, Zuithoff P, Rutten GE. Patient characteristics do not predict poor glycaemic control in type 2 diabetes patients treated in primary care. Eur J Epidemiol 2004; 19: 541-5. doi: 10.1016/j.clinthera.2006.03.005

48. Hoerger TJ, Segel JE, Gregg EW, Saaddine JB. Is glycemic control improving in U.S. adults? Diabetes Care 2008; 31: 81-6. doi: $10.2337 / \mathrm{dc} 07-1572$

49. Shah BR, Hux JE, Laupacis A, Mdcm BZ, Austin PC, van Walraven C. Diabetic patients with prior specialist care have better glycaemic control than those with prior primary care. J Eval Clin Pract 2005; 11: 568-75. doi: 10.1111/j.13652753.2005.00582.x

50. Hawthorne K, Tomlinson S. Pakistani Moslems with Type 2 diabetes mellitus: effect of sex, literacy skills, known diabetic complications and place of care on diabetic knowledge, reported self-monitoring management and glycaemic control. Diabet Med 1999; 16: 591-7. doi: 10.1046/j.1464-5491.1999.00102.x

51. Salcedo-Rocha AL, Garcia de Alba-Garcia JE, Frayre-Torres MJ, Lopez-Coutino B. Gender and metabolic control of type 2 diabetes among primary care patients. Rev Med Inst Mex Seguro Soc 2008; 46: 73-81. 